\title{
Invited Discussion on: Vision Loss Associated with Hyaluronic Acid Fillers-A Systematic Review of Literature
}

\author{
James E. Zins ${ }^{1}$ (D) Andrew Kochuba ${ }^{1}$
}

Received: 27 December 2019/Accepted: 30 December 2019/Published online: 28 February 2020

(C) Springer Science+Business Media, LLC, part of Springer Nature and International Society of Aesthetic Plastic Surgery 2020

Level of Evidence $V$ This journal requires that authors assign a level of evidence to each article. For a full description of these Evidence-Based Medicine ratings, please refer to the Table of Contents or the online Instructions to Authors www.springer.com/00266.

The authors provide a thorough systemic review of the rare but devastating complication of visual loss following hyaluronic acid soft tissue filler injection. The article touches on many important aspects related to this complication including the pathophysiology, the importance of the central upper mid-face "danger zones," the means of minimizing this untoward event and the relative effectiveness of various methods of reversal with hyaluronidase.

While all would agree that visual compromise following filler injection is catastrophic, it is unclear how commonly this occurs. However, we can put its likelihood in some perspective. According to The International Society of Aesthetic Plastic Surgery (ISAPS) International Survey on Aesthetic Procedures in 2018 [1], more than 3,700,000 HA filler injections were performed by plastic surgeons worldwide in 2018 alone. This represents an $11.6 \%$ increase compared to 2017 . This review could identify only 44 confirmed cases of which only two occurred in the USA. A recent review estimated the incidence of ischemic filler events (tissue ischemia as well as visual loss) at 3-9 per 10,000 injections. Therefore, these are rare but not unheard-of events [2].

The two most devastating complications following soft tissue filler injections include (1) local soft tissue ischemia and (2) visual compromise. While both involve inadvertent

James E. Zins

zinsj@ccf.org

1 Department of Plastic Surgery, Cleveland Clinic, 9500 Euclid Avenue, A60, Cleveland, OH 44195, USA intravascular injection of hyaluronic acid, local tissue loss leads to vascular occlusion through antegrade intravascular injection and occlusion of end vessels. Blindness, on the other hand, occurs when inadvertent intra-arterial injection of a peripheral branch of the internal carotid system or connecting branches between the internal carotid and the external carotid artery systems occurs. Pressure of the injection overcomes systemic pressure leading to retrograde flow through the internal carotid system back to the ophthalmic or retinal artery. When pressure of the injection stops, antegrade flow results in a filler embolus into the ophthalmic or retinal artery [3].

Most important, however, is the tolerance of the affected tissue to ischemia. With local soft tissue ischemia, the clinician has hours or days for reversal because of the relative tolerance of the skin to ischemia. However, neural tissue is much more sensitive, and with retinal or ophthalmic artery occlusion, the window of opportunity is measured in minutes. Primate animal studies have suggested that after $90 \mathrm{~min}$, irreversible visual changes occur [4]. However, what this time period is in humans is unknown and may be shorter. Herein lies the problem. In addition, conceptually, while effective reversal of fillerinduced local ischemia can be consistently accomplished by bathing the soft tissue surrounding the occlusion, [5] this is more difficult with visual loss because the retinal artery lives within the optic nerve and only a small retroorbital portion is available for direct enzymatic access by hyaluronidase [6].

Some of what was found is not surprising. The majority of patients treated for visual loss were between 20 and 40 years of age. This is consistent with those patients most likely to request filler injections. Visual loss most commonly resulted from filler injections in the central upper face "danger zone": the nose, the glabella and the 
forehead. This is due to the close connections between the external carotid and the internal carotid arterial systems. Interestingly, there were no incidents of blindness from central injections in the lower face, lips or chin. The authors document that surprisingly little filler is needed to create visual problems. Although the majority of injections leading to visual loss were $2 \mathrm{ccs}$, as little as $0.2 \mathrm{cc}$ resulted in visual impairment. Pain, ptosis, and ophthalmoplegia are frequent symptoms and signs accompanying visual loss, and these findings are most often immediate or occurs within $10 \mathrm{~min}$. It should also be noted that for those patients developing ophthalmoplegia, more than $70 \%$ completely recover. However sensory strabismus due to visual loss often develops and when it does surgical treatment is often necessary [7].

Analyzing the data regarding successful treatment from the literature cited is extremely difficult because neither accurate documentation of visual loss nor objective analysis of recovery is consistently performed. In addition, with partial visual compromise, patients fully recover with or without retrobulbar injections. This suggests that patients with partial loss may well recover spontaneously without invasive maneuvers. To reverse blindness, the hyaluronidase must diffuse across the dural layers to reach the intradural retinal artery in a short period of time. Delorenzi states that $0.1 \mathrm{~mL}$ of hyaluronic acid filler immersed in $1 \mathrm{~mL}$ of 150 units per cc of hyaluronidase takes four hours to hydrolyze. He therefore suggests that permanent visual damage is most likely to occur before hydrolysis of the filler embolus can be accomplished [4].

Finally the question remains: What to do should sudden visual loss occur at the time of filler injection? Should or should not retrobulbar injection be performed? For that patient with documented complete visual loss spontaneous recovery does not occur. It therefore may behoove the injector to become familiar with retrobulbar techniques if not for this patient population alone. Remember no technique is risk free. Neither large blunt needles nor small sharp needles, neither small aliquots of injection nor constant motion when injecting make this procedure fail-safe.
There are high-risk areas and low-risk areas. There are no "no-risk" areas for facial filler injections [4].

\section{Compliance with Ethical Standards}

Conflict of interest The authors declare that they have no conflicts of interest to disclose.

Human and Animal Rights This article does not contain any studies with human participants or animals performed by any of the authors.

Informed Consent For this type of study informed consent is not required.

\section{References}

1. International Society of Aesthetic Plastic Surgeons (ISAPS) International survey on aesthetic cosmetic procedures performed in 2018. ISAPS Global Survey Press Release. 3 Dec 2019

2. Beleznay K, Humphrey S, Carruthers JD, Carruthers A (2014) Vascular compromise from soft tissue augmentation: experience with 12 cases and recommendations for optimal outcomes. J Clin Aesthet Dermatol 7(9):37-43

3. Carruthers JD, Fagien S, Rohrich RJ, Weinkle S, Carruthers A (2014) Blindness caused by cosmetic filler injection: a review of cause and therapy. Plast Reconstr Surg 134(6):1197-1201. https:// doi.org/10.1097/PRS.0000000000000754

4. Hayreh SS, Weingeist TA (1980) Experimental occlusion of the central artery of the retina. I. Ophthalmoscopic and fluorescein fundus angiographic studies. Br J Ophthalmol 64(12):896-912

5. DeLorenzi C (2019) Discussion: assessing retrobulbar hyaluronidase as a treatment for filler-induced blindness in a cadaver model. Plast Reconstr Surg 144(2):321-324. https://doi.org/10.1097/PRS. 0000000000005861

6. DeLorenzi C (2014) Complications of injectable fillers, part 2: vascular complications. Aesthet Surg J 34(4):584-600. https://doi. org/10.1177/1090820X14525035

7. Yang HK, Lee Y, Woo SJ, Park KH, Kim JS, Hwang JM (2019) Natural course of ophthalmoplegia after iatrogenic ophthalmic artery occlusion caused by cosmetic filler injections. Plast Reconstr Surg 144(1):28e-34e. https://doi.org/10.1097/PRS. 0000000000005702

Publisher's Note Springer Nature remains neutral with regard to jurisdictional claims in published maps and institutional affiliations. 